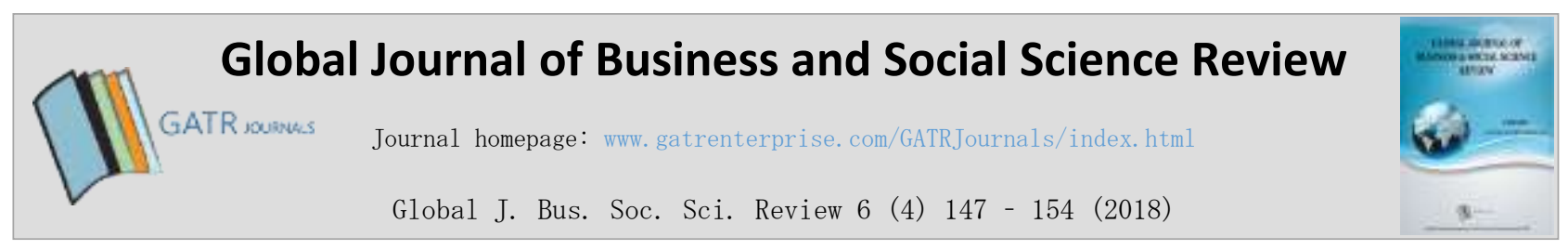

\title{
Telecommunication Sector Reform in Southeast Asia: A New Rationality
}

\author{
Riko Hendrawan, ${ }^{1 *}$ Kristian W.A. Nugroho ${ }^{2}$ \\ ${ }^{1,2}$ Telkom University, Jl. Gegerkalong Hilir No. 47, 40251, Bandung, Indonesia
}

\begin{abstract}
Objective - The telecommunications industry in Southeast Asia continues to grow, as evidenced by the market penetration that continues to increase from $3.8 \%$ in 2000 to $71.1 \%$ in 2017 . However, although the number of subscribers and revenue from telecommunication operators continued to grow between 2008 to 2017, the data shows that the EBITDA margin and ARPU value decrease with the growth rate (CAGR) $-1.12 \%$ and $-4.42 \%$.

Methodology/Technique - This study measures and analyzes the efficiency of 14 operators in Southeast Asia between 2008 to 2017 by using the Data Envelopment Analysis (DEA) method.

Findings - The results show that of the 14 telecom operators examined, Telkomsel (Indonesia) was the most efficient operator with an efficiency value of 0.97 and contributed from subscriber and revenue output variables which far exceeded the average of other operators. The most efficient telecommunication companies thereafter were StarHub (Singapore) and SingTel (Singapore) with an efficiency rating of 0.96 and 0.95 as represented from ARPU output variables that far exceeded the average of other operators.

Novelty - True move operators became the telecommunication companies with the lowest efficiency because the value of its output variables (subscribers, revenue and ARPU) was far below average and did not show any positive correlation to its efficiency value.
\end{abstract}

Type of Paper: Empirical.

Keywords: Data Envelopment Analysis (DEA); Efficiency; Telecommunication Industry; Southeast Asia.

JEL Classification: M1, M10, M19.

\section{Introduction}

The telecommunication business is a growing business in Southeast Asia, as evidenced from the number of subscribers which continue to increase from year to year. Statistics show an increase of telecom service subscribers from 2008 to 2017 by $10.07 \%$. The product sales by telecom companies has increased significantly since 2008, with the total number of subscribers rising 177,772,786 to 463,954,335 subscribers in 2017. However, when seen from the EBITDA margin of these telecom companies in the same period (2008-2017), the average growth rate is not in line with the growing number of subscribers.

\footnotetext{
* Paper Info: Revised: August 11, 2018

Accepted: December 6, 2018

* Corresponding author: Riko Hendrawan

E-mail: riko_hendrawan@yahoo.com

Affiliation: Faculty Economic and Business, Telkom University, Indonesia
} 
Indeed, there is a decreasing trend (CAGR -1.12\%). Similarly, as the revenue from telecom companies in Southeast Asia (2008-2017) continues to grow (CAGR 6.08\%), the value of ARPU (Average Revenue Per User) continues to decline (CAGR $-4.43 \%$ ).

The trend in the Southeast Asian telecom industry shows that the profit margin (EBITDA margin) tends to decrease when the accumulation of income increases which indicates that there was a tendency of expenditure numbers (operating expenses) to increase. Likewise, the fact that the value of ARPU decreases while the number of subscribers and income continues to increase indicates the existence of inefficient productivity. Hence, there is a need to research the efficiency of these telecom companies. Efficiency in general can be interpreted as the use of the smallest resources to get the greatest results. Efficiency in terms of company productivity is related to the allocation and use of resources owned by the company (Farrel, 1957). Data Envelopment Analysis (DEA) is one of the methods used to measure non-parametric efficiency, meaning it does not require assumptions in the form of distribution from the population to be tested. In addition, the DEA method has advantages over other methods because it can accommodate many input and output variables.

Measuring the efficiency of an enterprise is one way to evaluate company performance. Performance evaluation is based on the measurement of the activities of an organization through analysis of factors such as the unit costs, profit per unit, and others. The measurement of performance is often expressed in the ratio of the output divided by input. This ratio is generally used in efficiency measurement (Cooper, 2007). It can generally be said that efficiency is one parameter measurement that shows how a unit achieves the maximum output from the smallest input. The greater the output and the smaller the input, the greater the efficiency value will be.

Benchmarking can be measured by several methods, either with an average approach or a frontier approach (Saxena et al., 2009). Some previous researchers such as Baysal, Altun and Toklu (2007), Kang (2007), Moriwaki, Era, Osajima and Umino (2009), Sharma, Momaya and Manohan (2010), Torres and Bachiller (2011), Masson, Jain, Ganesh and George (2016), and Suleiman, Hemed and Wei (2017) use DEA to measure the efficiency of telecom companies in Turkey, Taiwan, Asia-Pacific, India, Europe and Tanzania. Hendrawan and Sumantri (2013) use DEA to measure the efficiency of mutual funds in Indonesia and Alfarisi and Hendrawan $(2010,2012)$ use DFA to measure the efficiency of banks in Indonesia

\section{Literature Review}

Data Envelopment Analysis (DEA) is a non-parametric method in operation and economic research which is used to measure the production efficiencies of the Decision Making Unit (DMU) in which the production process involves multiple input factors and output factors (Charnes et al., 1978). Avkiran (1999) defines DEA as a technique for measuring the relative efficiency of different organizational units which is capable of uncovering precise relationships between diverse inputs and outputs that cannot be accommodated through the traditional ratio analysis. The DEA method was originally developed by Charnes et. al. (1978) by calculating the efficiency of each DMU in converting inputs to outputs. DEA defines the efficiency of each DMU as the ratio of the weighted sum of output to the weighted sum of inputs. Output is the product and service produced by the unit, while input is the resource used to produce the output. Units with an efficiency value of $1(100 \%)$ are considered as efficient and values of less than $1(100 \%)$ are considered as inefficient.

Baysal, Altun and Toklu (2007) conducted research on one of the largest telecom operators in Turkey, Turk Telecom. The data from 82 provinces of Turk Telecom coverage were analyzed and compared with the two-stage DEA method, which was a CCR model for obtaining efficiency and cross-efficiency values to rank the efficiency values from all provinces. The inputs used for the DEA method were the number of personnel, number of service failures and amount of expenditure. While the outputs used were the number of telephone lines which corresponds to the number of subscribers and the income from ADSL services. Based on the first phase, 11 provinces have the highest efficiency (1). In the second phase with cross-references, 11 provinces 
have the most efficient value. That research makes several suggestions for the improvement of Turk Telecom service quality and customer satisfaction in some low-efficiency provinces.

Meanwhile, Kang (2007) analyzes the changes in production and cost efficiencies in telecom companies in Taiwan (Chunghwa Telecom Company) before and after privatization. To compare the allocation of input resources between these two periods, this study uses input-orientation DEA and Cost-DEA to calculate the cost efficiency. The variables used as inputs include total assets, total number of employees, and total capital expenditures, while the variables used as output include the income from fixed communication networks and non-fixed communication networks. The study uses annual report data from between 1966 and 2004. The results show no significant improvement in efficiency in Chunghwa Telecom Company after privatization.

Another study was conducted by Moriwaki, Era, Osajima and Umino (2009) on the telecom industry in the Asia-Pacific region using panel data between 1993 and 2004. That research uses a Stochastic Frontier (SF) method to calculate the Technical Efficiency based on telecom input variables including aggregated output, capital which was calculated based on perpetual inventory method of telecommunication investment, the number of employees, and raw materials in the form of fixed-telephone numbers and mobile phones. The results reveal that the efficiency of the telecom industry in the United States is much higher than in developing countries such as the Asia Pacific. The difference in the value of technical efficiency between countries is influenced by the population, the ratio of cellular phone users to total telephone subscribers, privatization, and internet adoption rates.

Likewise, Sharma, Momaya and Manohan (2010) also examine the performance of the telecom industry in India using the Data Envelopment Analysis (DEA) method to evaluate the competition of telecom operators, particularly in terms of efficiency. An input oriented DEA model was applied to measure the technical efficiency and scale efficiency of 10 telecom firms. The input variable used was the number of customers, while the output variable used was revenue value. The results of that research shows that from 10 telecom operators, 3 large operators were considered efficient: Bharti Airtel, Vodafone, and Aircel with an efficiency value of 1 . While other operators with a much smaller market share lacked efficiency.

Torres and Bachiller (2011) conducted a comparison of the efficiency of 11 privatized telecom operators from 1997 to 2005 and explored the possibility of whether privatization plays a role in increasing efficiency. The research was conducted using dual oriented input CCR model DEA. The input variables used in the efficiency analysis were the number of employees and total assets, while the output variable used was the operating income. The results show no significant growth in efficiency during the observation period; not all companies were able to adapt to market competition and inefficient companies would continue to operate in a monopoly despite the free market competition.

Similarly, Hendrawan and Sumantri (2013) examined the efficiency of mutual funds in Indonesia between 2007 and 2011. The measurement of efficiency was conducted on 105 mutual funds, which consisted of 29 stock funds, 38 mixed funds, and 39 fixed income mutual funds. The research was conducted using a nonparametric approach of Data Envelopment Analysis (DEA) method. It uses the input variables of front-end load, redemption fee, and expense ratio, while the output variable used was profit (return). From the 29 stock mutual funds, Commonwealth Life Investra Equity had the highest index (1) and Trimegah - Capital trim had the lowest index. From the 38 balanced mutual funds, CIMB-principal Dollar Fund (1) had the highest index and First State Indonesian Multistrategy (0.1276) had the lowest index. While from the 39 fixed income mutual funds, Brent Permanent Fund (1) had the highest index and Stable Bond Fund had the lowest index (0.355781).

Masson, Jain, Ganesh and George (2016) evaluated the performance of telecom service providers in India by measuring their operational efficiency and service delivery effectiveness. The research data was collected from 11 private telecom companies from 31 December 2012. This study used the two-stages of DEA. The first phase represents how efficiently a unit uses its infrastructure and resources to produce better service quality, while the second stage represents how effective the company communicates and provides the service 
to its users. The results show that companies with a high index in terms of operational efficiency and service delivery also exhibit a high profitability.

Additionally, Suleiman, Hemed and Wei (2017) evaluate the efficiency of 7 mobile operators in Tanzania from 2010 to 2016. The methodology applied was the Non-Radial Slack-Based Measure (SBM) Data Envelopment Analysis (DEA) in each operator. The next step was to use the Super-SBM model to efficiently rank the DMU based on its super-SBM value where the super-SBM values can be more than 1 . The input variables administered in the research were: Average Voice Total Local Tariffs, Average Voice East Africa Tariffs, Average Voice International Tariffs, Average Local SMS Tariffs, and Average International SMS Tariffs. Meanwhile, the output variables were: Average Subscription Market Share, Average Registered Subscriptions, Average Total Local Traffic Shares, Average Internals Traffic Shares, and Average Mobile Money Subscriptions Market Share. This study concludes that of the 7 firms studied, only 3 were considered to be efficient: Vodacom-Tanzania, Airtel-Tanzania, and Tigo, with a SBM score of 1. The remainder of the companies were considered to be inefficient: Zantel, Smart, Halotel, TTCL.

\section{Research Methodology}

The data used in this study is secondary data obtained from the financial statements of the companies between 2008 to 2017. As for the input variables, capital expenditure, operating expense, personnel expense, and total assets were used. Revenue, number of subscribers and ARPU were used as the output variables. Based on current data of the GSM Association, there were 53 telecom companies in 11 countries in Southeast Asia which were active and registered in the GSM Association. However, based on a purposive sampling technique, the criteria of this study included: (1) Telecom companies in Southeast Asia that are registered with the GSM Association and the stock exchanges of each country, (2) companies with a positive growth prospect of stock for the study period, (3) companies with a minimum subscriber number of 1,000,000 and (4) companies that have published their annual financial reports for 2008-2017. From these criterion, there were 14 telecom operators from 5 Southeast Asian countries selected: Telkomsel, XL Axiata, Indosat from Indonesia; Starhub, Singtel and M1 from Singapore; Celcom, DiGi, Maxis from Malaysia; Globe Telecom and Smart / PLDT from the Philippines; and AIS, dtac Telenor and TrueMove from Thailand. The data was collected based on the predetermined input and output variables, which was then analyzed using the Data Envelopment Analysis method. In finding the efficiency value of each DMU using the DEA method, the following equation was applied:

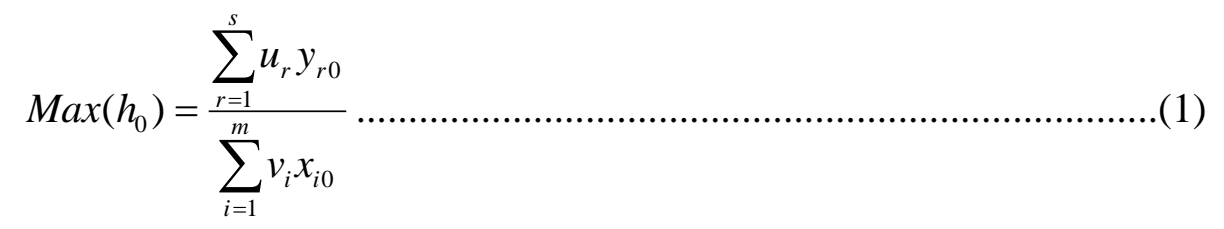

Where:

$$
\frac{\sum_{r=1}^{s} u_{r} y_{r j}}{\sum_{i=1}^{m} v_{i} x_{i j}} \leq 1 \quad ; j=1, \ldots, n \quad ; u_{r}, v_{i} \geq 0 \quad ; r=1, \ldots, s \quad ; i=1, \ldots, m
$$

$y_{r j}=$ value of the output variable (revenue, number of subscribers, ARPU)

$x_{i j}=$ value of the input variable (capital expenditure, operating expenses, personnel expense, total asset) 


$$
\begin{aligned}
& u_{r}=\text { weight of output variable } \\
& v_{i}=\text { weight of input variable }
\end{aligned}
$$

\section{Results and Discussions}

\begin{tabular}{|c|c|c|c|c|c|c|c|c|c|}
\hline \multirow[b]{2}{*}{ Ranking } & \multirow[b]{2}{*}{ Operators } & \multirow{2}{*}{$\begin{array}{l}\text { Efficiency } \\
\text { Score }\end{array}$} & \multicolumn{7}{|c|}{ Pearson Correlation Coefficient } \\
\hline & & & Subscriber & Revenue & ARPU & CAPEX & OPEX & $\begin{array}{l}\text { Per. } \\
\text { Exp }\end{array}$ & Tot.Asset \\
\hline 1 & Telkomsel & 0.97 & 0.3228 & 0.2830 & $\begin{array}{l}- \\
0.3352\end{array}$ & -0.2649 & 0.1973 & 0.1154 & 0.3363 \\
\hline 2 & StarHub & 0.96 & -0.5231 & -0.2534 & 0.7329 & -0.5342 & $\begin{array}{l}- \\
0.2513\end{array}$ & $\begin{array}{l}- \\
0.4394\end{array}$ & -0.3629 \\
\hline 3 & SingTel & 0.95 & -0.5608 & -0.4218 & 0.7704 & -0.5329 & $\begin{array}{l}- \\
0.4636\end{array}$ & $\begin{array}{l}- \\
0.4305\end{array}$ & -0.6174 \\
\hline 4 & AIS & 0.94 & 0.5768 & 0.7088 & $\begin{array}{l}- \\
0.2345\end{array}$ & 0.1887 & 0.4229 & $\begin{array}{l}- \\
0.1405\end{array}$ & -0.5786 \\
\hline 5 & DiGi & 0.92 & 0.6858 & 0.7355 & $\begin{array}{l}- \\
0.6104\end{array}$ & -0.3729 & 0.6256 & $\begin{array}{l}- \\
0.6409\end{array}$ & -0.2733 \\
\hline 6 & M1 & 0.89 & -0.8619 & -0.1749 & 0.8294 & -0.1955 & $\begin{array}{l}- \\
0.4049\end{array}$ & $\begin{array}{l}- \\
0.4696\end{array}$ & -0.6830 \\
\hline 7 & Maxis & 0.88 & -0.4801 & -0.2996 & 0.4416 & -0.5798 & $\begin{array}{l}- \\
0.7601\end{array}$ & $\begin{array}{l}- \\
0.2572\end{array}$ & -0.4496 \\
\hline 8 & PLDT & 0.86 & -0.3460 & -0.0712 & 0.4537 & -0.5859 & $\begin{array}{l}- \\
0.6703\end{array}$ & $\begin{array}{l}- \\
0.3314\end{array}$ & -0.4056 \\
\hline 9 & $\begin{array}{l}\text { XL } \\
\text { Axiata }\end{array}$ & 0.85 & -0.3053 & -0.4642 & 0.0013 & -0.2954 & $\begin{array}{l}- \\
0.6124\end{array}$ & $\begin{array}{l}- \\
0.6714\end{array}$ & -0.5050 \\
\hline 10 & ISAT & 0.84 & 0.5615 & 0.4578 & $\begin{array}{l}- \\
0.4848\end{array}$ & -0.2769 & 0.2661 & $\begin{array}{l}- \\
0.0752\end{array}$ & -0.2215 \\
\hline 11 & Celcom & 0.78 & 0.0191 & 0.0505 & 0.5192 & -0.7405 & $\begin{array}{l}- \\
0.3057\end{array}$ & $\begin{array}{l}- \\
0.4100\end{array}$ & -0.4033 \\
\hline 12 & Globe & 0.75 & -0.3248 & -0.4320 & 0.3006 & -0.3846 & $\begin{array}{l}- \\
0.6690\end{array}$ & $\begin{array}{l}- \\
0.3908\end{array}$ & -0.3579 \\
\hline 13 & Dtac & 0.72 & 0.0335 & 0.1162 & 0.0871 & -0.6110 & 0.0114 & $\begin{array}{l}- \\
0.3601\end{array}$ & -0.0612 \\
\hline 14 & TrueMove & 0.69 & -0.1676 & -0.3555 & $\begin{array}{l}- \\
0.3565\end{array}$ & -0.4657 & $\begin{array}{l}- \\
0.3561\end{array}$ & $\begin{array}{l}- \\
0.1679\end{array}$ & -0.4671 \\
\hline
\end{tabular}

Table 1. Efficiency Score and Pearson Correlation Coefficient Between Variables with Operators's Efficiency Value

The findings of this research show that the telecom operator in Southeast Asia with the best efficiency value is Telkomsel (Indonesia) with a value of 0.97 . Telkomsel's efficiency value was positively correlated with their number of subscribers $(0.3228)$ and revenue $(0.2830)$. This means that efficiency in Telkomsel was influenced by their large number of subscribers and the value of revenue earned.

StarHub (Singapore) has the second highest efficiency value after Telkomsel. Starhub's ARPU variable has a high coefficient value (0.7329). This means that the ARPU value greatly contributed to StarHub's efficiency. In addition, there was a contribution from the reduction of input variable value to StarHub efficiency value, proven by the negative correlation between the variables where the Capex value is -0.5432 ; Personnel Expense is -0.4394 and Total Assets is -0.3629 . This means that the reduction in the value of the 
input variables which was offset by increases in the ARPU variable placed StarHub as the 2nd most efficient operator.

SingTel (Singapore) has an efficiency value of 0.95 which places in third place. Its ARPU average value was higher than the others. It can be seen from the correlation between the variables with efficiency that there is a contribution from the reduction of the input variables to the increase of efficiency. This was evidenced by the negative correlation between the value of the Capex value (-0.5328), the Opex value (-0.4636), personnel expense $(-0.4305)$ and Total Assets $(-0.6174)$ to the value of efficiency. There is a positive correlation between the coefficient value of the ARPU variable which is equal to 0.7704 . This means that the efficiency value obtained by SingTel was effected by the increase of the ARPU value.

AIS (Thailand) was ranked fourth in terms of efficiency with a value of 0.94 . Its output variables of subscriber numbers and revenue were above average, while its ARPU value was lower than the average. Its efficiency value was positively correlated with the number of subscribers and revenue, where both variable values were above average in comparison to other operators. In addition, there is a negative correlation of total assets to efficiency with a coefficient value of -0.5786 . Thus, the value of AIS efficiency was the result of their large number of subscribers, the value of its revenue, and the reduction of its total assets.

DiGi (Malaysia) was ranked fifth in terms of efficiency. DiGi's output variables of subscriber and revenue were below average, however the ARPU value is higher than the average of other operators. There is a positive correlation between the value of subscribers and revenue with the efficiency values of 0.6858 and 0.7355 . On the other hand, there is a negative correlation between the input variables with a value of -0.6409 for efficiency of personnel expense. Thus, the efficiency value of DiGi's operators was the result of their number of subscribers, revenue, and the reduction of personnel expense.

Operator M1 (Singapore) was ranked sixth in terms of efficiency. The variable output of subscriber and revenue owned by M1 were below average. However, its ARPU value was above average. There is a negative correlation between all input variables owned by M1 with the efficiency value obtained. Likewise, there is also a positive correlation between the output variables of ARPU and the efficiency with a coefficient value of 0.8294 . Thus, the efficiency value of M1 was the result of the reduction of input variables and the magnitude of the ARPU value.

In this study, Maxis (Malaysia) operator was ranked 7th in terms of efficiency with a value of 0.88 . Its subscribers value was below average, while its revenue and ARPU values were above average. On the other hand, from the correlation coefficient between the variables, the values of the Maxis input variables had a negative coefficients with its efficiency values. Its ARPU variable was positively correlated with its efficiency value. Thus, the efficiency value of Maxis was the result of its ARPU value and the reduction of the input variable value, in particular Capex, with a value of -0.5798 and Opex with a value of -0.7601 .

Telecom operator PLDT (the Philippines) was ranked 8th in terms of efficiency, with an efficiency value of 0.86. Its subscriber and revenue values were above average, however its ARPU variable was below average. The value of its PLDT operator is negatively correlated with its efficiency value. While the value of its ARPU output variable has a positive correlation value of 0.4537 to its efficiency value. Thus, the efficiency value of PLDT was the result of its ARPU output variable value and a reduction of its input variables.

XL Axiata (Indonesia) obtained an average of 0.85 efficiency and was ranked ninth from 14 telecom operators in Southeast Asia. XL Axiata's subscriber output variable was slightly above average, as the revenue and ARPU of output variables were below average. Based on the correlation between input and output variables to the efficiency value obtained by XL Axiata, it was found that the input variables of XL Axiata were negatively correlated to its efficiency value. While the ARPU of the output variable was positively correlated to its efficiency value, albeit with a very small coefficient value (0.0013). Thus, the efficiency of XL Axiata was the result of a reduction in the value of input variables.

Indosat (Indonesia) earned an average efficiency rating of 0.84 and was ranked 10th out of 14 operators. Based on the Pearson Correlation between the input and output variables for Indosat's efficiency value, it can 
be seen that the output variable in subscribers and revenue has a positive correlation to the efficiency value whereby the coefficient value of subscribers was 0.5615 and revenue was 0.4578 . This means that the efficiency of Indosat Ooreedoo was the result of its number of subscribers and revenue value.

Celcom (Malaysia) obtained an efficiency rating of 0.78 and was ranked 11 out of 14 operators. Its output variables for subscribers and revenue were below average, while its ARPU value was above average. All input variables were negatively correlated with efficiency. Meanwhile, the output variables show a positive correlation with the efficiency value and the ARPU variable with a coefficient value of 0.5192 . This means that the efficiency value obtained by Celcom was the result of its ARPU variable and a reduction of its input variables.

The efficiency value obtained by Globe (Philippines) in this study was 0.75 meaning it is ranked 12 out of 14 operators. The average value of subscribers was above average, whereas its average value of revenue and ARPU was below average. The results show a negative correlation between the input variables and the efficiency value. Meanwhile the ARPU only presents a positive correlation to efficiency with a coefficient value of 0.3006 . Thus, the efficiency value of Globe was the result of a reduction of the value of its input variables (Capex, Opex, personnel expense, and total assets) and the value of ARPU.

DTac Telenor (Thailand) obtained an average efficiency rating of 0.72 and was ranked 13 out of 14 operators. The efficiency value of the Dtac Telenor was positively correlated with its output variables, although the coefficient values show a very weak correlation. Dtac Telenor's Capex value has a strong negative correlation to the efficiency value which is -0.6110 , and its expendable variable of personnel expense shows a negative correlation of -0.3601 to efficiency. Thus, the efficiency of Dtac Telenor was the result of a reduction of its Capex value and personnel expense.

TrueMove (Thailand) obtained the lowest average efficiency rating compared to the other 13 telecom operators, with a value of 0.69 . Based on the research results, the average of the output variable values including number of subscribers, revenue, and ARPU were below average. There was a negative correlation between the Capex value, Opex value, personnel expense, and total assets on the efficiency value, while there was no positive correlation between the output variables to the efficiency value. Thus, TrueMove's efficiency value was the result of a reduction of the value in the input variables.

\section{Conclusion}

Based on observations on the 10-year data per quarter, the value of the input and output variables in each telecom operator in Southeast Asia experienced growth from period to period. From the 1st quarter of 2008 to the 4th quarter of 2017, the annual growth was as follows: Capex grew 9.64\%, Opex grew 6.74\%, employee expenses grew $4.25 \%$, asset value grew $4.02 \%$, subscriber growth grew $10.07 \%$, annual revenue value growth grew $6.08 \%$, and ARPU declined $-4.43 \%$. Of the 14 active telecom companies in Southeast Asia for the period of 2008-2017, Telkomsel (Indonesia) was the most efficient operator with an efficiency value of 0.97. The most efficient telecom companies thereafter were StarHub (Singapore) and SingTel (Singapore) with efficiency ratings of 0.96 and 0.95 respectively. TrueMove had the lowest efficiency because the value of its output variables was far below the average and there was no positive correlation to its efficiency value. These conclusions are limited to the parameters of this paper.

This paper therefore suggests that telecom companies should increase efficiency by increasing the value of their output variables (in this case is the number of subscribers, the amount of revenue, and the value of ARPU). Further, telecom operators in Indonesia and Thailand can benchmark to operators in Singapore, Malaysia and the Philippines to raise the value of their ARPU.

\section{References}

Al-Farisi, A. S and Hendrawan, R. (2010). Measuring Efficiency as Intermediation Approach Between Conventional and Sharia Bank in Indonesia. Journal of Finance and Banking, 14 (3), 501-508. 
Al-Farisi, A. S and Hendrawan, R. (2012). Effect of Capital Structure on Bank Performance: Profit Efficiency Approach Islamic and Conventional Banks Case in Indonesia. International Research Journal of Finance and Economics. ISSN 1450-2887 Issue 86.

Avkiran, N. K. (1999). An Application Reference for Data Envelopment Analysis in Branch Banking: Helping the Novice Researcher. International Journal of Bank Marketing, 17(5), 206-220.

Baysal, M. E., Altun, D., and Toklu, B. (2007). An Efficiency Study in Turkish Telecommunication Company Using Data Envelopment Analysis. Beykent University Journal of Science and Technology. 1(1), 58-71.

Charnes, A., Cooper, W. W., and Rhodes, E., (1978). Measuring the Efficiency of Decision Making Units. European Journal of Operational Research, 2, 429-444.

Cooper, W. W., Seiford, L. M., and Tone, K. (2007). Data Envelopment Analysis: A Comprehensive Text with Models, Application, References and DEA-Solver Software. New York. Springer.

Farrel, M. J. (1957). The Measurement of Productive Efficiency. Journal of the Royal Statistical Society. Series A (General) 120(3), 253-290.

Hendrawan, R. and Sumantri, M.B.A., (2013). Efficiency of Indonesia Mutual Funds During 2007-2011 by Using Data Envelopment Analysis (DEA). Journal of Finance and Banking. 17, 99-110.

Kang, C. C. (2007). Measuring the Production and Cost Efficiency in Telecommunication Industry: The Taiwan Case. Proceedings of the Eastern Asia Society for Transportation Studies, 6.

Masson, S., Jain, R., Ganesh, N.M., and George, S.A. (2016). Operational Efficiency and Service Delivery Performance: A Comparative Analysis of Indian Telecom Service Providers. Benchmarking: An International Journal. 23(4). 893-915.

Moriwaki, S., Era, A., Osajima, M., and Umino, A. (2009). Efficiency Comparison of Telecommunication Industry among Asia-Pacific Region Countries. Institute for Information and Communications Policy.

Saxena, V., Thakur, T., and Singh., R. P., (2009). Evaluating the Performance of Mobile Telecom Operators in India. International Journal of Simulation System, Science and Technology IJSSST, 10(4).

Sharma, S., Momaya, K., and Manohar, K., (2010). Assessing the Performance of Telecommunication Industry in India: A Data Envelopment Analysis. Journal of International Business and Economy, 11(2), 29-47.

Suleiman, M. S., Hemed, N. S. and Wei, J. (2017). Evaluation of Telecommunication Companies Using Data Envelopment Analysis: Toward Efficiency of Mobile Telephone Operator in Tanzania. International Journal of eEducation, e-Business, e-Management and e-Learning. 8(3).

Torres, L., Bachiller, P., (2011). Efficiency of Telecommunications Companies in European Countries. Springer Science and Business Media.

Ure, J. (Ed.). (2008). Telecommunications Development in Asia. Hong Kong University Press. 